\title{
THE EUROPEAN MATHEMATICAL SOCIETY THE HOME FOR MATHEMATICS IN EUROPE
}

¿ Marta Sanz-Solé - Professor at the University of Barcelona - President of the European Mathematical Society - DOI: 10.1051/epn/2013402

\author{
The European Physical Society has invited me to write an article on the European \\ Mathematical Society (EMS) in its magazine, Europhysics News. This gives me a great \\ opportunity to provide the community of European physicists with an overview of a \\ learned society whose objectives are very similar to those of the European Physical \\ Society. The longstanding connections between our scientific communities make it \\ natural that we should strengthen the links between us.
}

M athematics and physics have a common history and an intertwined development. The scientific analysis of nature, the primary goal of physics, is intimately related to mathematics. Physical challenges have been the most important source of inspiration for mathematical theories. In turn, mathematics provides the language and logical structure for the rigorous description of physical theories. It is also a rich source for open questions. For example, it is via the language of mathematics that striking but not yet observed physical phenomena have been predicted.

Historical scientific celebrities, such as Archimedes, Averroes, Galileo, Newton, Gauss, Euler and Poincaré, just to mention a few, made revolutionary discoveries in both mathematics and physics. This ability to speak both languages so fluently and productively has become more rare. The terrific progress in both disciplines, has resulted in a differentiation. Nevertheless, cross-fertilization between the two fields continues to this day, and has spawned a hybrid field: mathematical physics.

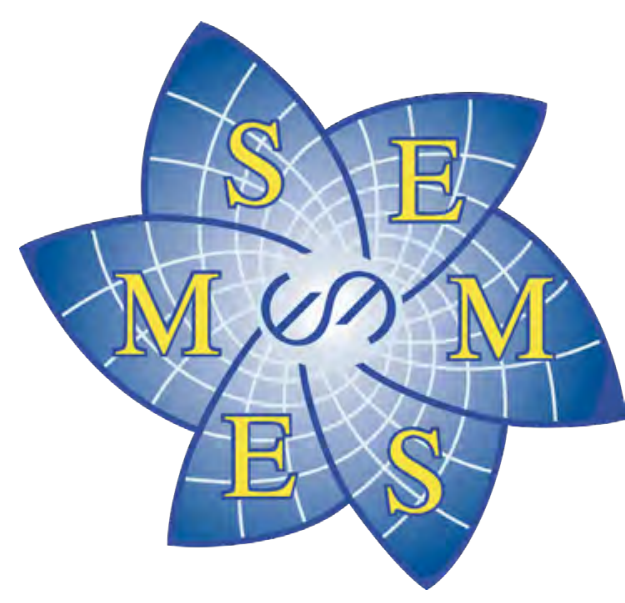

\section{Membership}

acted as a source of inspiration during the process of drafting its statutes. With a history of 22 years, the EMS has set up solid roots, reached its maturity and achieved a significant level of influence.

The EMS is much more than a federation of national mathematical societies. Its statutes provide for two types of membership: corporate and individual members. The former consists of mathematical societies, and research and academic organizations primarily devoted to promoting research in mathematics. Currently, EMS membership encompasses about 60 mathematical societies, 20 research centres and 10 academic institutions in European countries, along with about 3000 individual members. Looking closely at the organizations gathered behind these figures, it is fair to say that EMS is representing mathematics and is the voice of mathematicians in Europe.

The EMS website is the instrument for communication with our membership, and at the same time the showcase of the Society. However, there are also other ways to keep contact with The creation of national learned societies has developed in parallel with the differentiation between disciplines. Subsequently, with the establishment of the European Union and the strengthening of European identity, instruments to improve co-operation across Europe have become of the utmost importance.

It is in this context that the EMS was founded in 1990, and it is not surprising that the EPS, with an earlier creation, our members. For example, through the EMS Newsletter, a quarterly open access journal sent out to all EMS members in printed copies. All issues are available online on http://www.ems-ph.org/journals/journal.php?jrn=news . Between two consecutive editions of the EMS Newsletter, an electronic leaflet - the EMS e-News - with headlines, announcements, relevant news from committees, publications, etc., is sent out to all EMS members. 


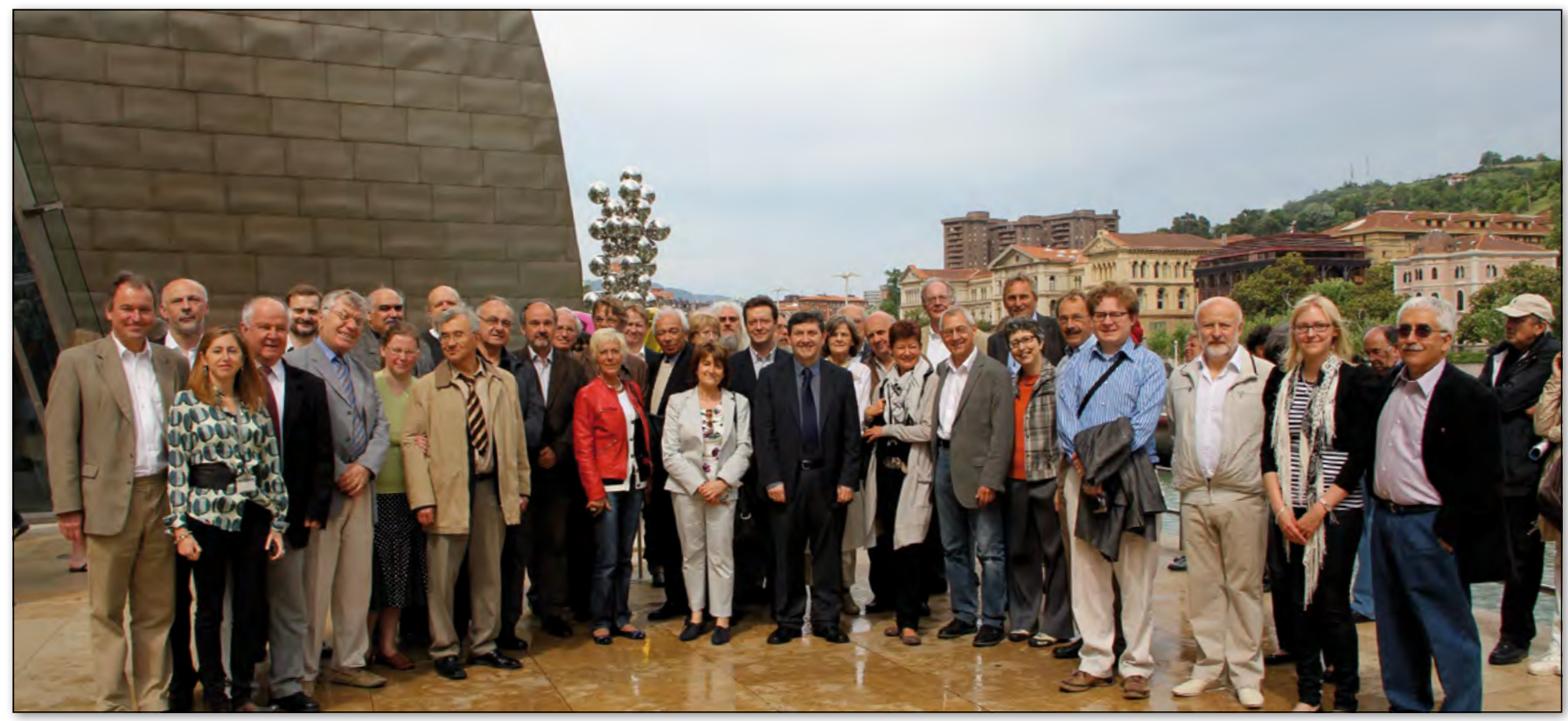

$\triangle$ EMS meeting at the Guggenheim Museum in Bilbao

The author, Marta Sanz-Solé

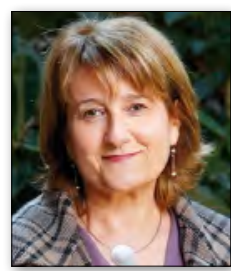

Since 2008, we hold an annual meeting of Presidents of EMS member societies. This is an occasion to follow closely their developments, to learn about their projects and concerns, and to get their feedback on important issues of common interest. It is also a place where synergies between different national societies are generated.

\section{Committees}

To a large extent, the main aims of the Society are developed within its committees. The Executive Committee (EC) has the special role of piloting, developing and monitoring actions resulting from discussions held and agreements taken in the Council -the General Assembly of the Society. Besides the EC, which is the governing board of the Society, there are ten EMS Committees: applied mathematics, developing countries, education, ethics, electronic publishing, meetings, publications, raising public awareness of mathematics, European solidarity, and women in mathematics. Their names clearly express their field of interest and action. Committees operate under considerable autonomy. However, they are requested to deliver a written report at each EC meeting. A member of the $\mathrm{EC}$ acts as liaison person between a given committee and the EC. This is to assure a permanent monitoring, and a smooth communication. The European Research Centres of Mathematics (ERCOM) is formally also an EMS committee. However, in practice it is a network of research mathematical centres in Europe under the umbrella of the Society. Most of the committees meet at least once every year. All have a webpage on the EMS website and most of them, their own website. The committee Raising Public Awareness of Mathematics is responsible for the website mathematics-in-europe.eu, a showcase for activities aimed to increase attraction of young students to mathematics and the interest of society in this discipline.

\section{Publications}

In 2001, the EMS launched its Publishing House (EMS PH) dedicated to the publication of high-quality peer-reviewed journals and books in all areas of mathematics. The plan arose as a necessity to provide a good service to mathematicians in the dissemination of mathematical knowledge, with the commitment of keeping the prices as low as is economically sustainable and maintaining a high standard in the editorial and publishing processes. Currently, the EMS $\mathrm{PH}$ is publishing fifteen journals, and books in nine specific series. They are distributed by the traditional subscription model and are among the least expensive mathematical journals. We are closely following and discussing the new trends in publishing, analyzing its impact in the current business model and possible ways to necessary changes in the future.

Together with FIZ Karlsruhe and the Heidelberg Academy of Sciences, the EMS is responsible for Zentralblatt MATH (ZBMATH). This is the world's most complete and longest running abstracting and reviewing service in pure and applied mathematics covering the period from 1868 to present.

\section{Scientific activities}

The most visible and largest scientific activities of the EMS are the quadrennial European Congresses of Mathematics (ECMs). The average number of participants is about 1000. At ECMs, the most recent and challenging trends in mathematics are exposed, while maintaining the unity of the discipline. Six years before the year of the Congress, the EC publishes a call for bids of organizers, considers the proposals and appoints a site committee, which makes a report to the EC. The final selection is left to Council. The first ECM was held in Paris, in 1992. It was followed by Budapest (1996), Barcelona (2000), 
Stockholm (2004), Amsterdam (2008) and Kraków (2012). The $7^{\text {th }}$ ECM will be in Berlin, on July 18-22, 2016. The scientific committee of an ECM is appointed by the EC. It is responsible for the selection of plenary and invited speakers, and special sessions. The local organisers contribute to shaping the programme with the organization of poster sessions, panel discussions and outreach activities, like public lectures and exhibitions. With the co-operation of member societies, the EMS runs Joint Mathematical Weekends, and other special activities. In the framework of collaborative agreements, it also organizes Summer Schools, one of them with the International Association of Mathematical Physics. The EMS nominates distinguished speakers at prestigious mathematical conferences and an EMS lecturer every year.

\section{Prizes}

The EMS Prize was established at the very early times of the Society. At most ten laureates are chosen and presented at each ECM. The Prize consists of an award to a young researcher not older than 35 years, in recognition of excellent contributions in Mathematics. As for today, about $20 \%$ of laureates won later the prestigious Fields Medal.

In co-operation with the European Consortium for Industrial Mathematics (ECMI) and the Fraunhofer Institute for Industrial Mathematics (ITWM), the EMS awards the Felix Klein Prize to a young scientist (or a group) in recognition of excellent contribution in Industrial Mathematics. Recently, a new prize funded by Springer Verlag was established: the Otto Neugebauer Prize in the History of Mathematics. It was firstly awarded in 2012.

\section{Closing}

This is a schematic description of basic facts on the EMS. In the global world, international learned societies are more that ever of strategic importance to support the advances of disciplines and to promote indispensable interactions. The current political structures in Europe and its strong historical identity, provide full meaning to and show the strong necessity for the existence of solid scientific umbrellas, platforms and networks within Europe. We can proudly state that EMS is playing this role for mathematics in Europe.

\section{Websites references}

EMS: www.euro-math-soc.eu/

EMS Publishing House: www.ems-ph.org

EMS Newsletter: www.ems-ph.org/journals/journal.php?jrn=news

Historical reference: www.ems-ph.org/journals/journal.php? jrn=news

\title{
[ Letter to the Editor $]$
}

\author{
by Herman C.W. Beijerinck \\ Eindhoven University of Technology, Eindhoven - The Netherlands \\ DOI: 10.1051/epn/2013403
}

\section{'Crossing borders'}

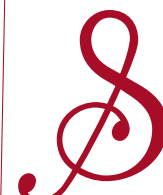
cientists are overwhelmed by publications in their field. We do our very best to keep up with literature and barely achieve this goal. Meetings with a wide scope are an excellent means of picking up new ideas. Even a 10-minute talk can be enough for an 'Aha Erlebnis' that inspires for further thought. It is not the time invested that is important; it is the open mind that sets the stage for this moment of inspiration.

General physics journals like Europhysics News should fill their niche in providing information to physicists. Keep in mind that EPS members are busy people, with little time for additional reading. Papers should be very well phrased, concise and have excellent illustrations.

Columns are a special class in such a journal. Their predictable appearance in every issue, their consistency in style and format, and their challenging content are ingredients that are highly addictive in a positive sense. Look at the successful column'Physics in daily life', and at the new column 'Opinion.' Both tease the reader into thinking about issues that are somewhat off the beaten track. At a general interest level, columns serve the same purpose as meetings. The next step for EPN is to stimulate the discussion on crossing borders to fields like theater, art, and music. Where do they meet, how do they interact? Think of the play on the Heisenberg/Bohr discussions in the middle of WW II. Did we discuss it in EPN? I can't remember we did. Think of the recent book and play'In free fall' by Juli Zeh, which has two physicists in the lead role. Who has read this wonderful book? Has it been discussed by physicists? These examples are very important for our profession, because they convey an image of physics to society. Like our Forum on Physics and Society, it represents an outreach into the public domain that we cannot neglect.

I propose a new column in EPN, tentatively called 'Crossing borders. It could be a broad link to society, by informing our readership on these interesting and important new developments. Culture is surely not the only neighboring field we can link to physics. What about psychology, philosophy, history and even religion? Would it not be interesting to see where we meet, what we agree on and how we disagree? Just think of the important role that paradigms have in our peer review system for new projects. 'Crossing borders' can have a major impact, both within EPS and in society at large.

EPN, I dare you to cross this line! - 